\title{
Contribuições para análise da gênese e uso coletivo do território em comunidades faxinalenses
}

\author{
Solange Struwka* (1) \\ Universidade Federal de Rondônia, Porto Velho, RO, Brasil
}

\begin{abstract}
Resumo: Apresentamos neste artigo indícios explicativos sobre a gênese, a transmissão e a manutenção ativa de costumes e tradições de uso coletivo do território pelos integrantes das comunidades faxinalenses. Os dados empíricos foram obtidos por meio de entrevistas com moradores de duas comunidades, localizadas na região centro-oeste do Paraná. Identificamos a gênese desse modo de vida atrelada a dois grupos étnicos ligados aos povos originários. Além disso, apresentamos evidências de como os conhecimentos e as práticas sociais foram repassados, aprendidos e mantidos ativamente por outros grupos sociais que constituem o que atualmente são as comunidades faxinalenses. A análise evidencia as relações dessa tradição com o acumulado histórico dos povos latino-americanos, contrapondo-se às interpretações abstratas e colonizadas que relacionam sua gênese às experiências europeias, assim como contribui para a compreensão desse modo de vida a partir das relações e práticas de apropriação social da natureza estabelecidas no território de uso coletivo.
\end{abstract}

Palavras-chave: enfoque histórico-cultural, comunidades faxinalenses, psicologia, uso coletivo do território.

\section{Introdução}

A transformação da Pachamama, Abya Yala ou Mãe Terra em latifúndios a serviço da produção de commodities tem sido pano de fundo da história dos povos originários que vivem no Brasil e na América Latina desde a colonização. A longa e constante luta contra a lógica de apropriação privada da natureza e do trabalho, iniciada há mais de 500 anos, segue sendo travada por diversos grupos, comunidades e coletivos que vivem em nosso país e continente. A rica diversidade cultural e social dessas populações possui uma marca em comum: a concepção de ser humano e de natureza baseada na busca por equacionar as necessidades individuais e coletivas, com o respeito aos limites impostos por leis e ciclos da natureza.

É fato que a incessante espoliação das riquezas na América Latina e o avanço da formação e do desenvolvimento do capitalismo periférico e dependente (Marini, 1973) foram acompanhados pelo extermínio e/ou pela negação das diversas sociedades e culturas que aqui viviam. Apesar disso, muitas delas seguem resistindo à opressão e genocídio. É do acumulado cultural dos povos originários, apropriado e transformado por outros grupos étnico-raciais, que esta pesquisa tratará das histórias e contextos de uma gente que não se rende diante da mercadorização imposta pelo "deus" capital, e dos grupos que resistem para manter outras formas de organizar a produção e a reprodução da vida comunitária. Em síntese, essas comunidades, cuja existência é real e concreta, são a mais forte expressão de que outras

\footnotetext{
* Endereço para correspondência: solange.struwka@unir.br
}

formas de organizar as relações de apropriação social da natureza - ou seja, de trabalho - são possíveis. Além disso, comprovam que a forma de produção material e imaterial de vida - hegemonicamente apresentada como única e onipotente -, subsumida na apropriação privada dos bens da natureza e do trabalho, não é destino nem fim último da humanidade, mas, sim, limite civilizatório da continuidade da nossa existência, pois está assentada sob a égide da superexploração irracional do trabalho e da natureza como recursos ilimitados.

Nesse sentido, o estudo apresenta indícios explicativos sobre a gênese, a transmissão e a manutenção ativa de costumes e tradições de uso coletivo do território. Os dados empíricos foram obtidos por meio de entrevistas realizadas com moradores de duas comunidades faxinalenses localizadas num mesmo município da região centro-oeste do Paraná. A pesquisa foi realizada entre os anos de 2016 e 2019 (Struwka, 2019a). Nesse período, foram feitas três imersões em cada comunidade, com duração de duas semanas para cada imersão - ocasiões em que a pesquisadora permaneceu na casa dos moradores entrevistados ou de lideranças locais. Dessa forma, foi possível acompanhar a rotina de trabalho e lazer das famílias, participar e contribuir nas práticas cotidianas, tanto familiares quanto comunitárias, e compreender suas histórias e contextos. As conversas-entrevistas foram gravadas e transcritas literalmente.

Não identificaremos o nome do município em que as comunidades estão localizadas, a fim de manter o sigilo e o anonimato dos entrevistados. Ressaltamos que os territórios de uso coletivo seguem em intensa disputa. Durante a última imersão, em julho de 2019, 
as lideranças estavam sendo ameaçadas e o território corria riscos de ser grilado, novamente, por uma empresa madeireira aliada a órgãos do Estado.

O enfoque histórico-cultural orientou a condução desta investigação, especialmente a construção teóricometodológica de Lev S. Vygotski. Com base nessa concepção, consideramos cultura como tudo o que foi desenvolvido pelo ser humano, desde os primeiros instrumentos de madeira e pedra até a construção de significados que dão sentido ao mundo do qual o sujeito faz parte. Os mitos e a religião também são compreendidos como instrumentos simbólicos. Assim, entende-se que tudo o que existe na natureza a partir da intervenção direta ou indireta da ação humana é produção cultural. Inicialmente, essa intervenção não é feita de forma planejada, consciente ou intencional, mas, sim, como estratégia de adaptação ativa ao meio, com o objetivo de solucionar problemas e dificuldades - e com as possibilidades encontradas na vida real e concreta. Fundamentalmente, é a partir de suas práticas em relação com a natureza, com outros seres humanos e com o acumulado e sistematizado cultural e histórico que o ser humano produz a sociedade e a cultura a que pertence. Em essência, o ser humano é um ser cultural, inclusive nos aspectos biológicos e fisiológicos (Beatón, 2005, 2015; Marx, 1858/2011, 1846/2007; Vygotski, 1931/2012; Vygotski \& Luria, 1930/1996).

Assim, compreende-se que a gênese e o desenvolvimento do psiquismo (cognição, afeto e volição) são produtos da vida real e concreta vivida pelo ser humano ao longo de todo o seu desenvolvimento em sociedade. São, essencialmente, síntese da unidade entre a atividade e a comunicação que se materializa nas relações sociais, ou interpessoais, e que é apropriada ativamente pelo sujeito, por meio da complexa dinâmica da atribuição de sentido às experiências vivenciadas (Beatón, 2017; Vygotski 1933/1996). Assim, se devemos compreender os princípios que orientam o sistema de relações que organiza a atividade e a comunicação em cada sociedade - valores, ideias, comportamentos, ações, crenças que são valorizadas ou rechaçadas em cada geração -, é da mesma forma fundamental compreender como essa organização social (consciente ou não explicada; planejada ou espontânea) influencia cada sujeito na apropriação ativa desses conteúdos e na constituição de sua singularidade (Beatón, 2005, 2015).

Dessa maneira, ressaltamos que afirmar a natureza social e cultural do psiquismo humano não significa recair em leituras mecanicistas e empiristas, considerando-o uma cópia direta ou linear do contexto. Pelo contrário, reafirmamos sua dinâmica única, com leis, princípios e explicações próprios, estando (para nós), até o momento, mais bem integradas e explicadas na lei da gênesis do desenvolvimento do psiquismo, da mediação e da vivência - compreendida como a unidade indivisível entre o meio e as particularidades do sujeito (Beatón, 2005, 2017; Vygotsky, 1933/1996). Essas sistematizações e explicações devem continuar sendo analisadas e trabalhadas coletivamente, como bases para a construção da nova psicologia - concepção que orientará as análises e explicações presentes nesta pesquisa.

\section{Caracterização das comunidades faxinalenses}

O Mapeamento Social dos Faxinais no Paraná, realizado entre 2005 e 2007, identificou a presença de 227 comunidades faxinalenses no estado, com estimativa populacional de aproximadamente 9.500 famílias. Essas comunidades estão distribuídas na mesorregião sudeste e nas regiões Metropolitana de Curitiba, centro-sul e centrooriental. Apesar da grande quantidade de comunidades mapeadas, os pesquisadores apontam para a ausência de números definitivos, já que não foi possível efetivar a investigação em todas as regiões do estado (Souza, 2008).

Tavares (2008) identificou a participação de quatro grupos sociais que contribuíram na formação e no desenvolvimento das comunidades faxinalenses. O primeiro grupo é composto pelos povos originários que ocupavam o Sul do Brasil, em especial os fugidos das ocupações jesuítas. O segundo é formado por homens e mulheres, negros e negras, que subvertiam o destino de escravização fugindo das fazendas em busca de terras onde pudessem viver com liberdade. O terceiro grupo é formado pelos camponeses que conseguiram escapar do massacre produzido pela Guerra do Contestado, conflito ocorrido no planalto Catarinense entre 1912 e 1916, cujo motivo foi a usurpação, pelo Estado brasileiro, das terras já ocupadas por camponeses para serem doadas à empresa multinacional Lumber (Tonon, 2002). O último grupo a se integrar nas comunidades faxinalenses foi o de imigrantes europeus. Provindos principalmente do Leste Europeu, em maior número da Ucrânia e da Polônia, além dos portugueses, italianos e alemães, esses imigrantes foram trazidos pelo Estado brasileiro com a missão de "branquear" o país e produzir desenvolvimento cultural e técnico, diante do que era compreendido como "atraso" que se relacionava à cultura dos negros e caboclos que habitavam o Sul do país (Moura, 1988).

Esses grupos são heterogêneos e apresentam particularidades na relação com os territórios de uso comum, a depender das condições e dos interesses do grupo envolvido. Nesse sentido, não é possível generalizar a história de formação das comunidades faxinalenses como algo homogêneo em todas as regiões, tampouco negar as contradições e os conflitos existentes entre os grupos étnico-raciais, como veremos na análise desta pesquisa.

No que diz respeito às características fundamentais desse modo de vida, destaca-se o uso comum do território, nomeado criadouro ou faxinal. Nesse espaço, as famílias constroem suas casas, criam os animais à solta e extraem os recursos naturais, como a erva-mate, o pinhão, a madeira etc.. Essas atividades são seu principal meio de sustento. Nas áreas de uso coletivo, a mata nativa 
é mantida e manejada por meio do extrativismo. Para além do território de uso coletivo, parte das famílias possui pequenas áreas para plantar cereais, tubérculos e outros cultivos, utilizados na alimentação familiar, como complemento na alimentação dos animais, para vender aos comerciantes ou para as trocas comunitárias. A dinâmica de produção desses alimentos se diferencia de comunidade para comunidade, assim como se alteram os acordos sobre o acesso e o uso dos bens naturais presentes no território de uso coletivo (Tavares, 2008).

Outras particularidades desse modo de vida envolvem a troca de dias de trabalho entre os moradores, tanto na produção quanto na manutenção do território de uso coletivo; a adaptação da produção dos animais à solta e a manutenção da floresta; e a possibilidade de viver e usar o território coletivo sem ter o título de posse ou propriedade da terra, especialmente quando existem familiares, compadres ou pessoas e famílias próximas morando no território de uso coletivo (Tavares, 2008).

A partir dessas formas particulares de apropriação dos bens naturais, no ano de 2005 , as comunidades faxinalenses foram inseridas na categoria de povos e comunidades tradicionais - categorização que lhes abriu possibilidades de reconhecer formalmente seus territórios como de uso e posse coletiva, forma de titular a terra até então inexistente no Brasil.

\section{Leituras hegemônicas sobre a origem das comunidades faxinalenses}

Quanto às explicações sobre a gênese desses costumes e tradições, materializados nos territórios geridos pelas famílias que vivem nas comunidades faxinalenses, identificamos várias pesquisas que se debruçaram sobre essa temática; destacaremos aquelas que consideramos mais relevantes. Antes de abordá-las, entretanto, julgamos ser necessário fazer uma análise crítica dos estudos das diferentes formas de apropriação coletiva dos bens comuns, especialmente do território e da terra, no Brasil. Constatamos um limite na análise histórica das terras de uso comum, pois em significativa parte das pesquisas as interpretações se iniciam no período da colonização ou da divisão das capitanias hereditárias (1534) - como se antes desse período não houvesse nada relevante ou, ainda mais grave, como se $\mathrm{o}$ acumulado das sociedades e culturas que aqui já existiam não tivesse sido apropriado por diferentes grupos sociais, inclusive aqueles que ainda hoje resistem à propriedade privada e ao latifúndio. Devido aos limites de espaço deste artigo, vamos nos deter apenas às explicações e interpretações sobre as comunidades pesquisadas, enfatizando que elas também foram influenciadas por essas concepções.

Um dos primeiros trabalhos realizados sobre os faxinais é o de Horácio Martins de Carvalho (1984), que atribuiu a formação do criadouro comum ao resultado histórico da criatividade dos trabalhadores que possuíam a condição de pequena burguesia agrária da região.
A relação entre a formação das comunidades e a presença de uma burguesia agrária foi fortemente criticada devido aos equívocos teóricos e à transposição das análises de modelo europeu. Posteriormente, as investigações de Chang (1988) relacionaram o início da formação dos faxinais com a queda do tropeirismo e a alta da extração de erva-mate no final do século XIX. Para a autora, os caboclos, os fazendeiros e os colonos foram os protagonistas na formação dessas comunidades. Já Gevaerd Filho (1989) busca explicar o início das comunidades faxinalenses comparando seus acordos à formação do direito de compáscuo presente em Portugal. Com distinta interpretação, Nerone (2000) também se valerá dos costumes e tradições presentes em Portugal, contudo a autora localizará na Península Ibérica as raízes dos faxinais. Para ela, a história da tradição comunitária dos povos germânicos e romanos é o indício explicativo da formação das comunidades presentes no Brasil. Nas suas palavras, "evidencia-se que o uso da terra no Sistema Faxinal não constitui um modelo original brasileiro derivado de outras formações históricas, mas os indícios conduzem à interpretação de que sua gênese é herança ibérica, adaptada às circunstâncias regionais" (Nerone, 2000, pp. 37-38).

A pesquisa com maior envergadura e relevância nessa temática foi a de Tavares (2008). A partir de uma significativa sistematização de informações, o autor aponta a gênese das comunidades a partir da aliança entre a cultura de dois povos: os indígenas fugitivos do sistema de peonagem, das missões ou reduções jesuíticas e da escravização exercida pelos bandeirantes paulistas; e os negros africanos fugitivos que não formaram quilombos. Para o autor, a cultura faxinalense é uma formação a partir da união entre as práticas: (1) de terras de uso comum, realizada pelos indígenas e aprendida nas reduções jesuítas; (2) de criação de animais, realizada pelos ex-escravizados africanos fugitivos que a aprenderam nas grandes fazendas de gado do planalto de Curitiba; (3) da extração da ervamate, realizada pelos dois grupos sociais.

Se, por um lado, reconhecemos o esforço de sistematização e as análises históricas realizadas pelo autor, especialmente por reconhecer o papel dos povos originários na gênese de costumes e tradições repassados e aprendidos nas comunidades faxinalenses, por outro, apontamos alguns limites em suas análises. Atrelar a aprendizagem do uso coletivo do território, por parte dos povos originários, às reduções jesuítas nos parece um equívoco. Afinal, como viviam as diversas sociedades e culturas milenares que ocupavam a América e o Brasil? Será que o mais original e genuíno da cultura dos povos originários também deve ser atribuído aos feitos dos colonizadores?

Como já apontamos, consideramos que essas análises e interpretações têm relação com a negação das sociedades e culturas que viviam no Brasil e na América Latina, unida a interpretações abstratas que têm como base a história da Europa. Essa análise fica evidente na forma como o autor inicia suas considerações finais, quando afirma: "A prática de terras de uso comum no Brasil tem 
sua origem histórica na Península Ibérica. Em Portugal, na forma comunal dos Baldios, com o uso comum das terras e seus recursos naturais pelos camponeses portugueses" (Tavares, 2008, p. 731). Nessa interpretação, não são apenas as comunidades faxinalenses que têm sua gênese no continente "além-mar", como aponta o autor: "com isso, é possível concluir que as diversas formas de terras de uso comum, denominadas de Terras de Preto, Terras de Índios, Terras Soltas, Fundo de Pasto e outras, têm em parte, suas origens históricas em Portugal" (Tavares, 2008, p. 731).

Chamamos a atenção para essa questão, dado que a gravidade dessas interpretações está no fato de que elas seguem sendo hegemônicas - e isso alerta para a urgência de revermos nossas raízes históricas, a partir das particularidades da América Latina. A negação e a invisibilização do acumulado cultural dos povos originários reafirmam, mais uma vez, a necessidade de avançarmos na produção de conhecimento desde a nossa história e as experiências originais e genuínas aqui produzidas, superando a lógica da "centralidade" ideológica da Europa e dos Estados Unidos.

\section{Gênese e uso coletivo do território: análise desde o enfoque histórico-cultural}

Nossa investigação sobre a gênese de costumes e tradições de uso coletivo dos territórios faxinalenses foi construída desde o ano de 2014. Durante seis anos, estive em contato com famílias das comunidades que se localizam em distintos municípios do Paraná. Dessas diferentes experiências, construídas na base de muito diálogo, dois elementos se repetiram em observações e relatos. O primeiro foi a diversidade étnico-racial na composição das comunidades, pois, como já descrito anteriormente, vários grupos étnico-raciais se "integraram" no uso coletivo dos territórios. O segundo foi a ausência de explicações, por parte dos moradores, sobre a história de formação dos costumes e tradições faxinalenses, assim como sobre os princípios que orientam e organizam essa particular forma de realizar ações, comportamentos e práticas. As respostas recebidas, repetidas na maioria das comunidades, foram: "é um costume aprendido com os mais velhos"; "a gente aprendeu assim com os antigos, e segue fazendo"; "quando nasci, já era assim", "ah, mas isso já vem de bem antes, é coisa dos mais velhos".

Junto a essas explicações, eram atrelados relatos das experiências de perda dos territórios, especialmente por meio de tentativas e da efetivação de grilagem das terras de uso comum e sua transformação em propriedade privada. As vivências negativas, referidas como "individualização da terra", foram relacionadas aos sentidos e significados ligados às perdas, tanto das condições básicas de vida quanto de pessoas que tiveram que migrar forçadamente da comunidade. As tentativas e efetivações de grilagem e de privatização dos territórios, empreendidas por empresas privadas com apoio do Estado, também geraram muita violência, empobrecimento das famílias e submissão a trabalhos forçados ou assalariados. Esse contexto produziu vivências negativas que passaram a conformar necessidades, motivos, interesses, emoções e sentidos relacionados à manutenção do uso coletivo do território.

Compreendemos, portanto, que as explicações dadas pelos moradores sobre a gênese e a manutenção do uso coletivo do território ou de seus costumes e tradições, atreladas à herança familiar e fortalecidas pelas vivências negativas de privatização das terras e superexploração do trabalho, contribuem para que os sujeitos possam enfrentar os desafios da vida real e concreta, cotidiana. Fundamentalmente, as ideias, interpretações e explicações estão relacionadas à constituição da volição (vontade, força, desejo) que fortalece e orienta as ações em defesa de seus costumes e tradições relacionados ao uso comum. Contudo também entendemos que é preciso avançar na análise e na explicação dessa complexa e rica construção histórica e cultural - especialmente quanto à gênese e ao desenvolvimento desse modo de vida, mutuamente determinado por princípios, ideias e concepções materializados em suas relações sociais, ações, comportamentos e práticas.

Ressaltamos que a causa de as explicações sobre a gênese e o desenvolvimento dos costumes e tradições serem relacionadas às experiências concretas é, essencialmente, uma das expressões da intencional desigualdade produzida pela divisão de classe que impera em nossa sociedade. Essa estratificação impede o acesso da classe subalterna aos direitos mais básicos, como terra, trabalho, educação e saúde de qualidade, e à organização de processos produtivos cooperativos com tecnologias adaptadas às necessidades de cada trabalho e região etc. Em relação à educação escolar formal, por exemplo, constatamos que parte significativa dos adultos e idosos que vivem nessas comunidades é analfabeta ou semianalfabeta e, tristemente, acompanhamos a baixa qualidade educacional oferecida a jovens, adolescentes e crianças.

Em permanente enfrentamento a esse contexto de negação e impedimento da apropriação e da elaboração conceitual da história e da epistemologia que os orientam, encontramos Ianá (nome fictício), uma idosa de 83 anos e grande sabedoria. É referenciada pelos moradores como conhecedora de histórias e contos da região e dos indígenas. Filha do único professor da comunidade, teve que se transformar em educadora para que as crianças não ficassem sem aula, processo que ocorreu de forma intempestiva devido a uma doença que seu pai desenvolveu e que o impedia de seguir com este trabalho. Assim, aos 14 anos, Ianá assumiu a docência e outras tarefas de cuidado com a escola e os educandos. Logo, diferentemente da maioria dos moradores, as descrições, ideias, sentimentos e explicações expressas por Ianá foram influenciadas e formadas por intermédio da leitura e da escrita e pela convivência com o pai, que também lia e se interessava por história. Destacamos esse ponto por entendermos que a leitura e a escrita produzem transformações significativas na constituição 
do sistema psíquico e possibilitam ao sujeito relacionar-se com a realidade, com a história e consigo mesmo de outra forma, a partir do uso de conceitos (Vygotsky, 1931/1996).

Durante os diálogos-entrevistas, Ianá relatou sobre o "encontro" entre os diferentes grupos que compõem sua árvore genealógica. Uma parte de seus ascendentes provém de um grupo que veio de outra região, são chamados "paulistas". A outra parte é formada por pessoas que já viviam no território onde a comunidade está localizada e integravam a diversa composição dos povos originários. $\mathrm{O}$ encontro e a construção da convivência, como historicamente ocorreu no Brasil e na América Latina, foram de submissão, violência e captura das mulheres, de seus corpos e conhecimentos. Uma dessas histórias, relatadas por Ianá, é da avó de seu marido. Ianá a conheceu com idade avançada e a caracteriza como uma mulher de distinto acúmulo de conhecimento e sabedoria: "Eu conheci ela ainda, sabe?... Ela entendia de tudo, o que perguntasse pra ela, ela sabia, o tipo das plantas, remédios, tudo ela sabia" (Entrevista concedida em 02/03/2018). Sobre o início da história, Ianá compartilha':

\section{Pesquisadora: E ele [pai] contava como foi essa convivência?}

Não foi fácil. essa ... que eu te falei hoje, o tal falecido, ... que era avô do meu marido, tinha o rio São Pedro que desce aqui, [cita o nome de uma pessoa da comunidade que estava conosco] sabe muito bem do que eu estou falando, que é perto da casa do pai dela, e dai a falecida... descia nadar, parece que tinha uma porção [de indígenas], onde cai a cachoeira, né? E a falecida era moça, do convivio dos índios, dai ela descia tomar banho. E ela tinha uma flor de cravo no cabelo, sempre quando ela descia, por isso que eles deram o nome dela de [cita o nome da indígena], mas na verdade, na língua dos índios, eu nem sabia como que era o nome dela. E dai, o falecido ... começou a cobiçar ela, sabe? Mas, quando ela percebia que tinha gente perto dela, ela corria, sabe? Aquele terreno dos alteirão, [cita o nome da pessoa] que lá que era a tábua [tekoá] dos indios, a tábua [tekoá]! Que é um tanto de casa junto, né? A aldeia também dos índios, eles dizem. Então, dai ela corria dele! E ele foi se interessando, cobiçando ela: "como é que eu vou fazer pra mim conversar com essa india? Ela corre de mim". Disse que ele foi e se escondeu em uma oca de pedra, há muito tempo que ele estava cobiçando, e nesse dia, sabe? E ela tinha um assobiador na cintura, porque aquele assobiador deles, quando eles se sentiam em apuros, eles assobiavam ali e se escutava lá onde que tivesse, né? Dai ele foi e pegou ela, bem dizer, sequestrou, hoje em dia é sequestro, né? Pegou a india e correu com a índia, porque, quando ele viu que ela

1 Os nomes citados nas entrevistas foram suprimidos a fim de impedir a identificação das entrevistadas. Inseriremos ... para identificar a supressão dessa informação. estava com aquele coisa na cintura, ele já arrancou da cintura dela, ele deixou ela sem arma, né? E daí tinha a casa deles pra cá, que era do falecido... pai dele. Lá em cima, ali, onde nós tinha acampamento [da ocupação], mais pra cima ainda, onde era as terras, onde compraram ali, né? Daí disse que tinha a casa deles e ele chegou e bateu as portas e fechou ela dentro do quarto, mas disse que braba, Deus o livre! Só que eu digo pra você, não foi, assim, a convivência deles, foi muito dificil, porque eles [Guaranis e Kaingang] eram os donos da terra, né? Eles não queriam que entrassem outras pessoas. Dai disse que ele fechou ela dentro do quarto, disse que levava um prato de comida, mas pense que ela queria comer ... Nossas comidas não era adequada, né? Disse que gritava e dava chutes, Deus o livre lá dentro, disse que ela ficou uma fera de brava. Tinha cama, tinha tudo ali, mas ela, Deus o livre, se enxergasse eles assim. Dai disse que foi indo, foi indo, dai um dia ela achou o assobio dele lá, ele levou o assobiador dela e esqueceu, ela foi se amansando pra comer alguma coisa, não ia morrer de fome mesmo, dai disse que ela pegou e assobiou naquele negócio, Deus o livre! Disse que veio o cacique, que é o chefe, né? E todo o bando! Dai disse que o véio saiu e pediu, né? O véio sabia, né? Pediu sinal de paz pra eles, que não queria briga com eles, né? Mas eles vieram pra matar eles tudo. Ela assobiou lá dentro da casa do rancho do véio, ela assobiou que eles vieram lá, subiram tudo ali. Subiram tudo lá, a sorte que a casa dele era uma casa boa. Daí disse que ele contou ali que dai ele queria casar, parece que deu algum sinal pra eles lá que queria paz e queria casar. Dai trataram o tal casamento com muito custo, disse que fizeram uma festa, ele contava, sabe? O falecido pai. Fizeram uma festa e eles não dançam que nem a outra turma dança, assim, eles dançam em roda. Dançaram em roda do casal que ia casar. Eles pescaram pra fazer a festa, sabe? Eles fizeram a comida deles, e o falecido [cita o nome do avô] fez a dele também, pra daí, cada um tinha um costume, né? Ele assou uma leitoa e tudo o que é coisa lá, e eles fizeram, disse que passava numa peneira, né? Era tipo uma polenta que eles faziam, sabe? Do milho, pra comer com peixe. Disse que, quando faziam festa, Deus o livre do tanto que eles pescavam, sabe? Mas dai casaram, o falecido [cita o nome do avô] casou com ela, mas porque ele pegou ela à força né. (Ianá, entrevista concedida em 02/03/2018)

O relato é mais um dos muitos casos em que a violência e a força foram utilizadas para a aproximação e a "convivência" entre os grupos que avançavam sobre o território ocupado pelos povos originários, como já analisados por diferentes pesquisadores, como Cunha (1992), Martins (1997) e Ribeiro (1968). Para nós, esse relato comprova não só a captura e o estupro das mulheres indígenas, mas também reafirma nossa 
tese sobre a existência das inter-relações que garantiram a passagem, a apropriação e a recriação do acumulado cultural milenar dos povos originários para outros grupos étnico-raciais. Nesse caso, o legado repassado e aprendido esteve circunscrito aos limites exercidos pelas relações de dominação e opressão. Contudo nem por isso deve ser ignorado como referências fundamentais para a particular e posterior forma de organizar as relações nos territórios faxinalenses.

Ianá descreve como grande parte do que conhece sobre a biodiversidade da região foi aprendida com a avó ou com os conhecimentos que ela e outras pessoas repassaram, compartilharam e trocaram, e aponta como referência os povos originários. No decorrer das caminhadas pelo quintal, mostrando a variedade de ervas, verduras e frutas cultivadas, Ianá afirma constantemente que uma das principais características desses povos era o cuidado, a seleção, a conservação e a reprodução das sementes e dos animais. Para ela, esse costume é atrelado à forma como organizavam a produção e a reprodução da vida coletiva, adaptada ativamente ao manejo da biodiversidade de cada região, fonte de sua sobrevivência e soberania alimentar. Ela ainda explica como esses conhecimentos e práticas foram repassados e aprendidos e se mantêm entre os moradores da comunidade.

\section{Pesquisadora: Como eles [indígenas] influenciaram?}

Continua até agora! É dificil ter uma pessoa aqui que não ligue. Tem em algum canto, mas é alguém que vem de lá do outro lugar, né? Já não é acostumado com o nosso costume. Mas nós fomos acostumados a tirar a semente... Tudo a minha sogra, todas as sementes boa, ela tirava pra plantar. Que às vezes nós precisava, um vizinho precisava porque não deu na lavoura dele, né? Ela repartia... Tudo que eu sei é dos indios. Porque os indios, eles paravam um pouco em um lugar e, de repente, na outra safra, eles estavam em outro lugar. Por quê? Eles carregavam as sementes! Tudo eles... eu não passo sem tirar uma semente. Eu vou cortar uma abóbora, já me lembro: eu tenho que tirar a semente, porque isso já está dentro da minha cabeça, que já veio da nossa familia, que nós precisamos! Eu vejo gente chupando laranja, que não é da nossa qualidade, e joga as sementes de laranja! Joga a semente de abóbora! Eu digo "essa não tem sangue de indio!". Eu guardo, eu guardo, planto, troco com os vizinhos. Por que é assim que mantém, né? A gente cuida, troca e também ganha dos outros. (Ianá, entrevista concedida em 02/03/2018)

Identificamos dois indícios centrais nos relatos apresentados. O primeiro é a presença da cultura dos povos originários em ações, comportamentos e práticas da comunidade. O segundo, unido ao anterior, é o compartilhar e a troca como princípios centrais na organização das relações entre as pessoas, no manejo da natureza e na organização do trabalho. Esses princípios se materializam na prática cotidiana de compartilhar sementes, frutos, mudas e animais - a fim de garantir a manutenção da diversidade e da soberania alimentar, como apontado por Ianá -, mas também na prática de uso coletivo do território. Se, por um lado, é fundamental destacarmos a referência à cultura dos povos Kaingang e Guarani, por outro, também destacamos que o compartilhamento e a solidariedade se mantêm e são recriados como estratégias essenciais e atuais na resolução dos problemas enfrentados na vida real e concreta, já que, como apontado por Ianá, garantem a diversidade alimentar, além de prevenir e resolver os problemas gerados por pragas, pestes e outros contratempos.

Rosa, moradora de outra comunidade faxinalense, situada na mesma cidade de Ianá, aponta o sentido de compartilhar as sementes e mudas:

\section{Pesquisadora: Qual o sentido de dividir as sementes, Rosa?}

Rosa: Ah, mas é assim que a gente aprendeu a fazer e faz. Veja, se eu tenho uma semente, divido com o vizinho, com aquele e aquele outro. Eu tenho e ele também tem! E se acontecer do meu não dar o dele vai dar, e assim a gente leva adiante as coisas. Ih, quantas histórias aqui de ter dado peste nas coisas e ter acabado com a sementeira e um conhecido lá do outro lugar trazer pra nós. (Rosa)

\section{Pesquisadora: Com quem a senhora aprendeu essas coisas, Rosa?}

Mas isso é do meu pai! Ele era bugre [caracterização étnico-racial aos que têm ascendência de povos originários], sabe, que te contei que a mãe dele era daquelas indias pega no mato. De certo isso já vem de sangue, né? Ele tinha um amor pela natureza que você nem sabe, menina! Tudo que lugar que ele ia ele trazia semente. No terreninho lá em baixo era lindo de ver, tinha tudo que tipo de planta, umas par que tem aqui, trouxe de lá. Então, isso já vem com a gente, vem dessa parte dele. (Rosa, entrevista concedida em 27/01/2018)

Assim como Ianá, Rosa carrega na história familiar várias formas de violência, a começar pelo sequestro das mulheres indígenas. Também traz consigo conhecimentos, sentimentos e práticas que fazem referência ao acumulado cultural desses povos - formas de vivenciar e organizar os trabalhos, aprendidas a partir da influência de seu pai e que foram mantidas e recriadas por ela e por outras pessoas, as quais seguem efetivando essas formas de se relacionar com a natureza e com os demais, reiterando que esses são modos de fazer avaliados e validados no cotidiano, como ela mesma aponta sobre o compartilhamento.

Apresentaremos outro trecho da entrevista com Ianá que evidencia a essencial influência da cultura dos 
povos originários na gênese do uso coletivo do território. Importa-nos avançar na análise de que apesar da violência e da opressão presentes no "encontro" e na "convivência" entre esses grupos, as relações, a comunicação e as práticas efetivadas possibilitaram a apropriação da cultura acumulada e sistematizada no decorrer de milhares de anos e seguem sendo a estratégia utilizada para a produção e a reprodução da vida social dos moradores que ocupam esses territórios.

\section{Pesquisadora: E em relação ao uso da terra, eles [pai e avó] contavam como era?}

Era de uso comum! Sempre, essas terras que tinha, era de uso comum. Pra criar, pra plantar. Não tinha esse negócio que "não, aquela terra é medido lá de sicrano", como agora tem, né? De primeiro, eu vou roçar aquela capoeira lá, ia lá, roçava e plantava e pronto, não tinha dono! Agora, isso era costume dos indios, eles faziam tudo no coletivo, os trabalhos, as comidas, a casa deles, era tudo assim, comum. (Ianá, entrevista concedida em 10/03/2019)

Nesse sentido, ao contrário de como explicam as pesquisas apresentadas no item anterior, o relato de Ianá nos possibilita fazer outra análise e atrelar de forma objetiva e histórica a gênese dessa forma de apropriação da natureza aos povos originários, nesse caso, às etnias Guarani e Kaingang que viviam na região. Para corroborar a análise, recorremos aos estudos antropológicos desenvolvidos por Souza (2002) sobre ambas as etnias. Notamos semelhanças entre a forma como esses povos se organizavam econômica e politicamente - e as comunidades faxinalenses. Das possíveis aproximações, podemos citar a economia voltada para suprir as necessidades familiares, compreendidas como as necessidades do grupo, e a posição central do alimento na produção. Outra semelhança se refere à organização das relações de trabalho, em forma de mutirão e por meio de práticas coletivas. De acordo com o autor, "o consumo e a circulação aldeã também se tornam viáveis, fundamentando um intricado sistema político-econômico baseado em princípios de prestações e contraprestações, como o é a reciprocidade" (Souza, 2002, p. 226).

Outro ponto de apoio aos indícios explicativos apontados são os registros da presença das etnias citadas na região Sul do Brasil, o que também contribui para superar a ideologia historicamente reproduzida de que as terras do Terceiro Planalto não estavam ocupadas e faziam parte de um "vazio demográfico" - "vazio" que precisava ser ocupado pelos "pioneiros conquistadores". Na contramão dessa história colonizadora, apoiamo-nos na pesquisa de Noelli e Lúcio Mota (1999), que traz os relatos escritos pelo espanhol Álvar Cabeza de Vaca, em 1542. O documento confirma a presença e a organização dos povos Guaranis e Kaingang onde atualmente estão localizadas as comunidades investigadas. Além disso, é o primeiro relato a apresentar a organização política e cultural desses grupos. Nas palavras dos autores: "havia uma divisão política entre esses diversos grupos de mesma matriz cultural, organizados politicamente em cacicados (conjunto de aldeias sob a liderança de um prestigioso cacique, que dominavam certas porções de territórios bem definidos)" (Noelli \& Mota, 1999, p. 3).

Junto com a confirmação da presença e da organização política desses grupos, os autores chamam a atenção para as alianças realizadas entre estes povos e os grupos de "brancos", a fim de resistir à escravização imposta tanto pelos invasores paulistas quanto pelas reduções jesuítas - elementos que fortaleceram nossa posição contrária a atrelar os indícios explicativos da gênese do uso coletivo do território à aprendizagem ocorrida nas missões. Os autores ainda destacam que é preciso superar as análises históricas dicotômicas de indígenas contra brancos, pois, nas palavras dos autores, "Deve-se considerar os grupos conquistadores europeus e seus interesses localizados; bem como os Guarani e os Kaingang, que eram inimigos e que, estrategicamente, estabeleceram alianças entre si" (Noelli \& Mota, 1999, pp. 5-6). Para nós, essas análises dicotômicas, além de negarem as relações objetivas e históricas da região e do país entre os povos originários e os diversos grupos sociais que invadiram essas terras, negam as referências a toda a cultura acumulada em milhares de anos e que foi repassada por meio das relações, da comunicação e das práticas desigualmente estabelecidas.

Como síntese, compreendemos que costumes e tradições efetivados nas comunidades faxinalenses são uma forma particular de se relacionar com as pessoas e com a natureza que foi produzida, repassada e aprendida por meio de um sistema de relações estabelecidas entre diferentes grupos sociais, tendo como principal referência o acumulado cultural dos povos originários no caso investigado, das etnias Guarani e Kaingang. No decorrer da história, de maneiras distintas e a depender dos interesses dos grupos envolvidos, esses costumes foram mantidos e aprimorados por diferentes grupos étnico-raciais, inclusive pelos imigrantes europeus que chegaram ao final do século XIX e início do século XX, especialmente poloneses e ucranianos. Estes grupos, mesmo tendo a posse e o título da terra, utilizam-na de forma coletiva com os demais moradores, evidência que comprova que essa forma de organizar o sistema de relações sociais não está atrelada a apenas um grupo étnico-racial, mas é uma das formas, das estratégias ou dos métodos de adaptação ativa do ser humano às condições da natureza e ao acúmulo social e cultural disponível em cada contexto e momento histórico.

Nesse sentido, compreendemos que as relações e práticas realizadas nas comunidades faxinalenses são mediadas por um acumulado de conhecimentos sobre ciclos $\mathrm{e}$ leis da natureza que formam ideias, sentimentos, motivações e uma concepção em que o compartilhamento e o cuidado são essenciais na relação que os membros das comunidades 
estabelecem com os outros e com a natureza. Analisamos que esse método de organizar as relações, a comunicação e as atividades produz nos sujeitos uma vivência agradável e positiva - baseada no próprio bem-estar e no bem-estar da família, da comunidade e da natureza - e, ao ser concretizado, dialeticamente, é validado de forma positiva e produz vontade, desejo e força para continuar sendo realizado dessa maneira. Em síntese, compreendemos que esses sujeitos possuem um método de organização da produção e da reprodução da vida social alicerçado na busca por equacionar as necessidades coletivas (moradores da comunidade) e no cuidado com a natureza, ligada fundamentalmente à cultura dos povos originários e, apesar de não estar explicado e elaborado, possuem uma particular concepção de ser humano, natureza e coletivo (comunidade), sendo a não elaboração desses conteúdos um dos limites que devem ser superados.

Evidenciamos ainda que a experiência negativa de transformação dos bens naturais em propriedade privada para exploração e acumulação individual criou a necessidade de que sujeitos e comunidades se organizassem contra a grilagem e a invasão de seus territórios. Uma das expressões dessa organização é a denominação e o reconhecimento da identidade social e política de ser parte dos povos e comunidades tradicionais do Brasil (Struwka 2019b). Contudo apontamos a importância de atrelar esse debate à gênese e ao desenvolvimento de um método de apropriação da natureza, e à sistematização e elaboração dos princípios que o orientam. Dessa forma, será possível que os próprios sujeitos analisem de forma crítica o que consideramos conformar um método e epistemologias particulares que se efetivam em suas relações, atividade e comunicação. Por outro lado, esse acumulado social e cultural poderá contribuir na organização de outras experiências de resistência à privatização dos bens comuns e à superexploração do trabalho, a partir da construção de relações saudáveis e respeitosas com a natureza e o ser humano.

\section{Considerações finais}

O objetivo deste artigo foi discutir os indícios explicativos sobre a gênese, a transmissão e a manutenção ativa de costumes e tradições de uso coletivo do território por parte dos sujeitos que constituem as comunidades faxinalenses. A partir das análises, compreendemos que essa forma de se apropriar dos bens naturais é uma estratégia ou método historicamente desenvolvido pelos povos originários - que, no caso investigado, se relacionam às etnias Kaingang e Guarani. Esse acumulado cultural foi repassado e aprendido, mantido e recriado ativamente por outros grupos étnico-raciais - apesar das relações com os povos originários terem ocorrido, na maioria das vezes, de forma desigual e violenta. Essa condição, unida à hegemonia colonialista e ao acesso restrito aos processos educativos críticos sobre a história do Brasil e da América, continua mantendo invisível a importância da cultura dos povos originários na formação social das comunidades faxinalenses e, acrescentaríamos, brasileira e latino-americana.
Além disso, os indícios explicativos presentes nesta pesquisa comprovam que o desenvolvimento dos valores sociais, morais e éticos não é uma estrutura fixa ou definida pelas condições biológicas ou fisiológicas. O que evidenciamos, com a análise dos dados empíricos, é que valores como o compartilhamento e a solidariedade foram aprendidos de forma ativa por cada sujeito, por meio de sua participação real e concreta num sistema de relações sociais, comunicação e práticas que foram organizadas a partir desses princípios, e, fundamentalmente, são valorizadas e validadas na prática pelas pessoas que vivem no território de uso coletivo. Assim, reiteramos que tais valores, ideias, explicações, sentimentos e necessidades são produzidos a partir da influência das relações familiares e comunitárias, e fazem parte das práticas realizadas para solucionar os problemas e aproveitar as possibilidades presentes na vida real e concreta.

Por fim, apontamos a importância de avançarmos na sistematização e nas análises críticas sobre como se formam e quais são os princípios que orientam esses outros modos de organizar as relações comunitárias e a apropriação da natureza. É preciso investigar como e por que esses grupos seguem mantendo seus costumes e se protegendo dos malefícios causados pela propriedade privada e pela exploração do trabalho do outro - ao menos nesses "redutos" que são os territórios de uso coletivo.

Com isso, não devotamos nenhum romantismo abstrato de que a solução da nossa questão social está nos povos originários, assim como não ignoramos contradições e limites presentes nessas sociedades, culturas e costumes. Por outro lado, acreditamos categoricamente que a particularidade dessas sociedades milenares nos darão contribuições imprescindíveis para seguirmos afrontando a desigualdade social produzida pelo hegemônico modo de acumulação e concentração de riqueza. Nesse sentido, é também função da psicologia compreender como a construção desses processos educativos, presentes na produção e reprodução da vida comunitária, produz outras ideias, explicações, sentimentos, consciência, concepção que medeiam suas ações, comportamentos e práticas.

Estamos convencidos, a partir das explicações e análises de Simón Rodriguez, Karl Marx, F. Engels, J. C. Mariátegui, L. S. Vygotski, Guillermo Arias Beatón e das experiências vivenciadas nesses anos de pesquisa e militância que, para construirmos a nova sociedade tão desejada, precisaremos fazer a síntese crítica e dialética das culturas originárias de Nuestra América, da nossa Abya Yala ou Pátria Grande para orientar o uso do melhor que foi produzido na sociedade capitalista. Em síntese, sem os conhecimentos que medeiam os princípios de respeito e cuidado com a natureza, e sem o desenvolvimento tecnológico bem empregado, humanamente utilizado, não seremos capazes de construir nossa segunda e definitiva independência, uma sociedade com distribuição equitativa e justa das riquezas para a satisfação das necessidades humanas. 


\section{Contributions for analyzing the genesis and collective land use in faxinal communities}

Abstract: This study present the explanatory evidences about the genesis, transmission and active maintenance of collective land use practices and traditions, employed by Faxinaleneses. Empirical data was collected by conducting interviews with members of two communities, located in the Midwest region of Paraná. This way of life originated with two ethnic groups descended from indigenous peoples. We discuss how knowledge and social practices were passed on, learned, and actively maintained by other social groups that constitute the current faxinal communities. The analysis emphasizes the relationship between this tradition and the history of Latin American peoples, against the abstract and colonized interpretations that relate its genesis to European experiences, contributing to understand this way of life based on relations and practices of social appropriation of nature, developed within collective land use.

Keywords: historical cultural approach, faxinal communities, psychology, collective use of territory.

\section{Apports pour l'analyse de la genèse et de l'usage collectif des terres dans les communautés faxinal}

Résumé : Cet article analyse la genèse, la transmission et le maintien actif des pratiques et traditions d'usage collectif des terres employé par les Faxinalenses. Les données exploratoires ont été recueillies en menant des entretiens avec les membres de deux communautés, situées dans la région centre-ouest du Paraná. Ce mode vie est issu de deux groupes ethniques descendant de peuples autochtones. Nous examinons comment les connaissances et les pratiques sociales ont été transmises, apprises et activement maintenues par d'autres groupes sociaux qui constituent les communautés faxinal actuelles. L'analyse met l'accent sur la relation entre cette tradition et l'histoire des peuples latino-américains, en s'opposant aux interprétations abstraites et colonisées qui rapportent sa genèse aux expériences européennes. On contribue à comprendre ce mode vie basé sur des relations et des pratiques d'appropriation sociale de la nature, développées dans le cadre d'un usage collectif des terres.

Mots-clés : approche historico-culturelle, communautes faxinal, psychologie, usage collectif du territoire.

\section{Contribuciones al análisis de la génesis y el uso colectivo del territorio en comunidades faxinalenses}

Resumen: En este artículo presentamos indicios sobre la génesis, la transmisión y el mantenimiento activo de las costumbres y tradiciones de uso colectivo del territorio, realizada por los integrantes de las comunidades faxinalenses. Los datos empíricos fueron obtenidos por medio de entrevistas realizadas a habitantes de dos comunidades ubicadas en la región Centro-Oeste de Paraná. Identificamos la génesis de este modo de vida vinculado a dos grupos étnicos, relacionados con los pueblos originarios. Además, mostramos evidencias de cómo los conocimientos y las prácticas sociales fueron transmitidas, aprendidas y mantenidas activamente por otros grupos sociales, que constituyen lo que actualmente denominamos "comunidades faxinalenses". El análisis evidencia las relaciones de esa tradición con el acumulado histórico de los pueblos latinoamericanos, contraponiéndose a las interpretaciones abstractas y colonizadas que relacionan su génesis a experiencias europeas, así como contribuye a la comprensión de ese modo de vida a partir de relaciones y prácticas de apropiación social de la naturaleza, realizadas en el territorio de uso colectivo.

Palabras clave: enfoque histórico-cultural, comunidades faxinalenses, psicología, uso colectivo del territorio.

\section{Referências}

Beatón, G. A. (2005). La persona en el enfoque histórico cultural. São Paulo, SP: Linear B Editora.

Beatón, G. A. (2015). La educación que produce y arrastra la formación y el desarrollo moral de la personalidad. Interfaces da Educação, 6(18), 9-28.

Beatón, G. A (2017). Vivência, atribuição de sentido e subjetivação da atividade, a comunicação e relações sociais. In M. E. M. Bernardes \& G. A. Beatón (Orgs.), Trabalho, educação e lazer: contribuições do enfoque
Histórico-Cultural para o desenvolvimento humano (pp. 143-214). São Paulo, SP: Escola de Artes, Ciências e Humanidades.

Chang, M. Y. (1988). Sistema faxinal: uma forma de organização camponesa em desagregação no centro-sul do Paraná. Londrina, PA: Iapar.

Carvalho, H. M. (1984). Da aventura à esperança: a experiência autogestionário no uso comum da terra. Curitiba, PR: Mimeografado. 
Cunha, M. C. (Org.). (1992). História dos índios no Brasil. São Paulo, SP: Companhia das Letras.

Gevaerd Filho, J. L. (1986). Perfil histórico-jurídico dos faxinais ou compáscuos. Revista de Direito Agrário e Meio Ambiente, (1), 45-69.

Marini, R. M. (2011). Dialética da dependência. In R. M. Marini, R. Traspadini, \& J. P. Stedile (Orgs.), Ruy Mauro Marini: vida e obra (2a ed., pp. 131-173). São Paulo, SP: Expressão Popular. (Trabalho original publicado em 1973)

Martins, J. S. (1997). Fronteira: a degradação do outro nos confins do humano. São Paulo, SP: Hucitec.

Marx, K. (2007). A ideologia alemã: crítica da mais recente filosofia alemã em seus representantes Feuerbach, B. Bauer e Stirner, e do socialismo alemão em seus diferentes profetas. São Paulo, SP: Boitempo. (Trabalho original publicado em 1846)

Marx, K. (2011). Grundrisse: manuscritos econômicos de 18571858: esboços da crítica da economia política. São Paulo, SP: Boitempo. (Trabalho original publicado em 1858)

Moura, C. (1988). Sociologia do negro brasileiro. São Paulo, SP: Ática.

Nerone, M. M. (2000). Terras de plantar, terras de criar Sistema Faxinal: Rebouças (1985-1997) [Tese de doutorado]. Universidade Estadual Paulista, Assis, SP.

Noelli, F. S., \& Mota, L. T. (1999). Índios, jesuítas, bandeirantes e espanhóis no Guairá nos séculos XVI e XVII. Revista Geonotas, 3(3), 1-6.

Ribeiro, D. (1968). Oprocesso civilizatório: etapas da evolução sociocultural. São Paulo, SP: Civilização Brasileira.

Souza, J. O. C. (2002). O sistema econômico nas sociedades indígenas Guarani pré-coloniais. Horizontes Antropológicos, 8(18), 211-253.

Souza, R. M. (2008). Mapeamento social dos faxinais no Paraná. Guarapuava, PA: Instituto Equipe de Educadores Populares. Recuperado de https://bit.ly/37r8A45
Struwka, S. (2019a). A formação da personalidade em camponeses que fazem o uso comum da terra [Tese de doutorado]. Universidade de São Paulo, São Paulo, SP.

Struwka, S. (2019b). Camponeses faxinalenses e os conflitos e lutas pela permanência na terra: questões entre a identidade coletiva e classe social. In Y. M. Fontes \& M. Patícia (Org.), História e lutas sociais: a classe que trabalha em movimento (pp. 75-89). São Paulo, SP: Educ.

Tavares, L. A. (2008). Campesinato e os faxinais do Paraná: as terras de uso comum [Tese de doutorado]. Universidade de São Paulo, São Paulo, SP.

Tonon, E. (2002). Ecos do Contestado: rebeldia sertaneja. Palmas, PR: Kaygangue.

Vygotski, L. S. (1996). El desarrollo sel pensamiemtno del adolescente y la formación de conceptos. In Obras escogidas - tomo IV. Madrid: Editorial Aprendizaje. (Trabalho original publicado em 1931)

Vygotski, L. S. (1996). La crisis de los siete años In: Obras escogidas - tomo IV. Madrid: Editorial Aprendizaje. (Trabalho original publicado em 1933)

Vygotski, L. S. (2012). La prehistoria del desarrollo del lenguaje escrito. In: Obras escogidas - tomo III. Madrid: Antonio Machado Libros. (Trabalho original publicado em 1931)

Vygotski, L. S. (2014). Pensamiento y linguaje In Obras escogidas - tomo II. Madrid: Antonio Machado Libros. (Trabalho original publicado em 1934)

Vygotski, L. S., \& Luria, A. R. (1996). Estudos sobre a história do comportamento: o macaco, o primitivo e a criança. Porto Alegre, RS: Artes Médicas. (Trabalho original publicado em 1930)

Recebido: 22/01/2021

Revisado: $10 / 04 / 2021$

Aprovado: 26/07/2021 